Document downloaded from:

http://hdl.handle.net/10251/43604

This paper must be cited as:

Serra Lluch, J. (2013). The versatility of color in contemporary architecture. Color Research and Application. 38(5):344-355. doi:10.1002/col.21734.

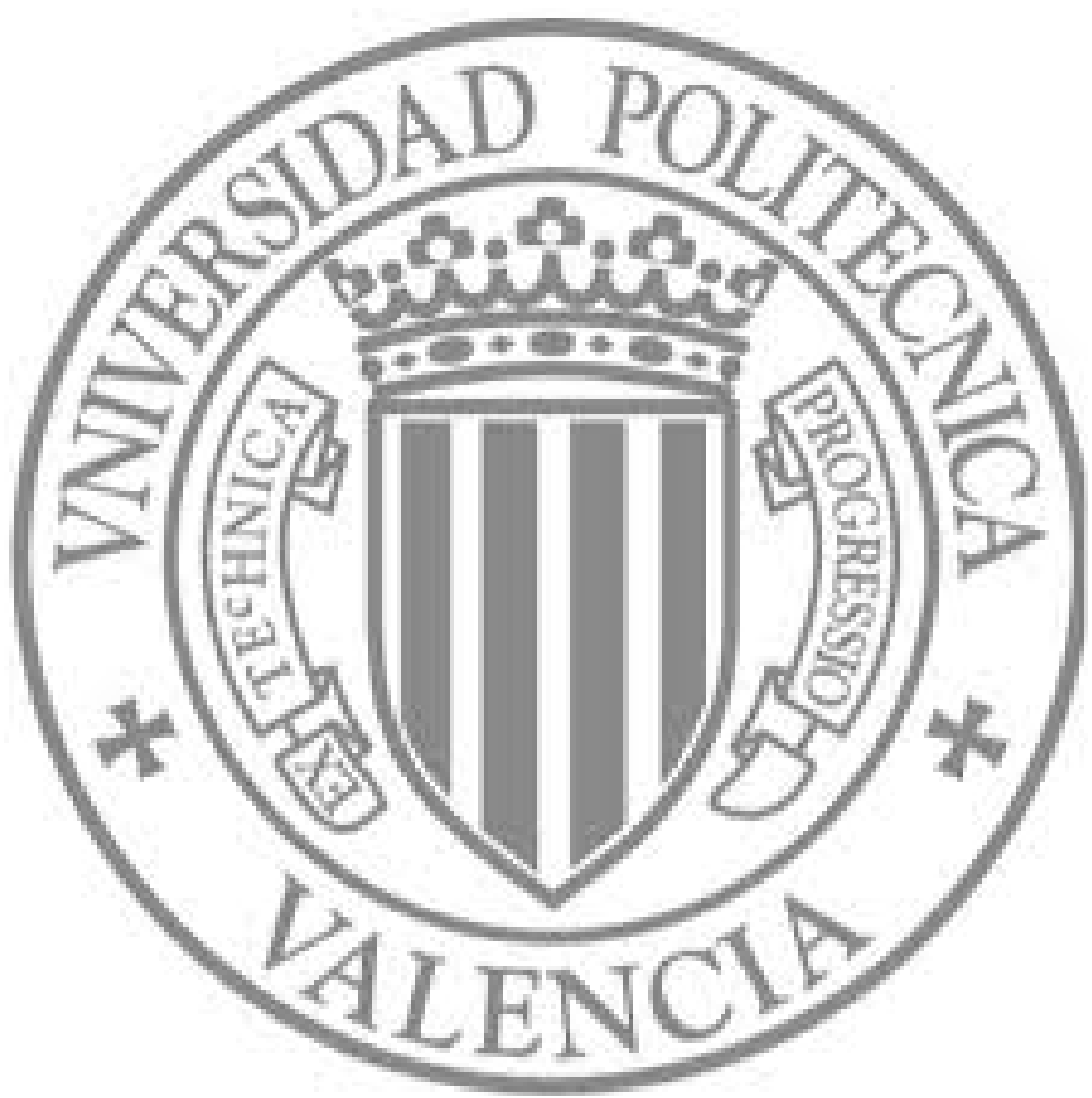

The final publication is available at

http://dx.doi.org/10.1002/col.21734

Copyright Wiley 


\section{The versatility of color in contemporary architecture}

\begin{tabular}{|r|l|}
\hline Journal: & Color Research and Application \\
\hline Manuscript ID: & Draft \\
\hline Wiley - Manuscript type: & Research Article \\
\hline Date Submitted by the Author: & $\mathrm{n} / \mathrm{a}$ \\
\hline Complete List of Authors: & $\begin{array}{l}\text { Serra, Juan; Escuela Técnica Superior de Arquitectura, Expresión Gráfica } \\
\text { Arquitectónica }\end{array}$ \\
\hline Keywords: & Architecture, Color Theory, Art, Spanish Color Committee, Design \\
\hline
\end{tabular}

\section{SCHOLARONE \\ Manuscripts}

\section{THIS IS THE PRE-PEER REVIEWED VERSION OF THE FOLLOWING ARTICLE:}

"The versatility of color in contemporary architecture"

COLOR RESEARCH \& APPLICATION

Volume 38, Issue 5, October 2013, Pages: 344-355, Juan Serra

Article first published online : 30 MAR 2012, DOI: 10.1002/col.21734

Which has been published in final format at:

http://onlinelibrary.wiley.com/doi/10.1002/col.21734/abstract 
The versatility of color in contemporary architecture

\author{
Juan Serra ${ }^{1}$ \\ 1 Color Research Team, Heritage Restoration Institute, Polytechnic University of Valencia, \\ Spain.
}

Keywords: Architecture, Color Theory, Art, Spanish Color Committee, Design

This article is, in part, the results of the thesis entitled: "The versatility of color in the composition of European contemporary architecture: artistic context, plastic strategies and intentions", headed by Professor Ángela Garcia, awarded a Mention Européenne on $19^{\text {th }}$ April 2010.

\begin{abstract}
Since the early twentieth century, there has been a noticeable move towards the versatility of color in architecture. This can be attested to through an analysis of the color of buildings designed by some of the leading modern and contemporary architects, and a critical review of works written about the colors used in their buildings. This analysis goes on to identify four concepts related to the term versatility: transformation, fragmentation, movement and novelty.

These four concepts help us to understand the way color is conceived and arranged in contemporary architecture. By doing so, we aim to re-establish the importance of color in the design of architecture, overcoming some former theoretical and practical prejudices stemming from the modern era.
\end{abstract}

\title{
INTRODUCTION
}

Buildings are objets d'art designed to fulfill long-term human requirements. This entails reconciling architecture's longevity with its adaptation to new functions or aesthetic needs. Historically, this ambivalence has been solved by color, which allows architectonic structures to be refreshed when new circumstances emerge: a new owner, the division of a property, style variations, etc. Architect Michael Riedij ${ }^{1}$ points out that "this is both the beauty and the tragedy of using paint to color buildings. It can be painted over at any time. Thus, expressing the building and its cultural significance is left to the whims of the janitor". Architects unquestionably avoid decisions about color being made by non-professionals but, at the same time and somehow, they largely renounce any expression of permanence. Since the early twentieth century, not only do buildings try to adapt to change, but they even use change as a resource for their own artistic expression. Architects, in collaboration with other artists, search for the expression of versatility in their work.

Versatility means being "able to easily change from one activity to another or be able to be used for many different purposes" ${ }^{2}$. To achieve versatility in buildings means to renounce permanence, to understand life as being contingent, Heraclitan, ever-changing, constantly evolving. Durability does not refer to everlasting objects, but rather to those that always try to reinvent themselves. Nowadays, architecture seems to be caught up in this dynamic of constant renewal, urged to deny its very self, becoming something new. It should be emphasized that versatility is not only the consequence of an artistic attitude and a change in the understanding of the discipline, but also the result of new plastic resources: building materials and design tools. Technological improvements have definitively helped to express versatility.

We consider that color is a useful path in the expression of versatility. This concept is achieved by using four different potentials for change: transformation, changes in the visual aspect of the buildings; fragmentation, changes in the integrity of the buildings; movement, changes in position; and novelty, changes in procedure and technology. This classification is based on a detailed study of some of the most renowned architects who pay careful attention to color in the design of their buildings, even though the structure is just a provisional understanding in an ever-changing reality, because "every building is a living creature: a piece which will be seen and interpreted differently by each generation. The best review is, therefore, the one that conciliates consideration on form and content" ${ }^{3}$. 


\section{COLOR TRANSFORMATION: CHANGES IN THE VISUAL ASPECT}

Transform means to "completely change the appearance or character of something or someone". Color is not able to change the real shape of architecture but rather its visual perception: geometry, dimensions, visual mass and texture. Color may present a contradiction between the real architectural shape and the one being perceived. As the perception of color is possible because there is a light source, an illuminated object and an observer ${ }^{4}$, we may say that every color transformation implies changes in one of these three variables. In relation to light, we will discuss possible color alterations due to light sources. In relation to the object, the discussion will cover transformations produced by alien reflections, changes in the object itself or variations by specially colored building materials. Finally, there are buildings which seem to transform as a consequence of observer's perceptive limitations, but with no changes in lighting, or in the object.

\section{TRANSFORMATIONS OF THE LIGHT SOURCE}

Surface color depends both on the nature of the light and its angle with respect to the object and observer. These changes in color are spontaneously produced as a consequence of certain atmospheric conditions and changes in daylight. Le Corbusier himself describes architecture as the "play of masses brought together in light" ${ }^{5}$. Contemporary artists such as Alain Bony ${ }^{6}$, collaborating with Jean Nouvel, "unashamedly attempts to create a work of art on the scale of a building to be spatially experienced under varying daylight and electric light conditions".

New artificial lighting systems may transform the color of architecture at night. A building could be a neutral screen with all sorts of changing colors projected over it (e.g. Burj Al Arab Hotel, col. Mark Major, arch. Tom Wright, Dubai, United Arabic Emirates, 1994-1999). Sometimes artificial light is white, but illuminates the reverse of a stained glass or a transparent surface, so the building's façade looks like an opaque plane during the day and turns into a great colored lamp at night (Figure 1).

Inner spaces also suffer transformations when changes occur in the characteristics of the penetrating exterior light. The angle incidence and the intensity of natural sunlight can be controlled with the use of mobile elements positioned along façades, like the brise-soleils, widely applied during modern times and up to the present day. Penetrating natural light may also be colored when passing through a pigmented transparent material: stained glass (e.g. Els colors nursery, RCR: architects, Manlleu, Barcelona, 2002), lace curtains (e.g. Ricola Factory, col. Adrian Schiess, arch. Herzog \& de Meuron, Laufen, Switzerland, 1986-1988), colored slats (Figure 2), etc. Space versatility is reinforced because interior colored surfaces are also illuminated with colored light that varies according to the weather and time of day.

Figure 1. Alianz Arena Stadium, Herzog \& de Meuron, Munich, Germany, 2005. Photo by Richard Bartz in http://commons.wikimedia.org/wiki/File:Allianz Arena zu verschiedenen Zeiten.jpg

Figure 2. Netherland Institute for Sound and Vision. Neutelings Riedijk Architects, Rotterdam, 2007. Photo by Lauren Manning in http://www.flickr.com/photos/28541331@N00/2318218999

\section{OBJECT TRANSFORMATION BY MEANS OF REFLECTION}

Materials able to reflect images, such as glass, mirrors or satin-finished surfaces, continuously change their aspect. A fugitive color, coming from an always changing reality, is superimposed over its real color. The reflection integrates the outside, the alien. The building takes possession of a reality with an infinite number of variables that change their color: vehicles, people, vegetation, etc. On the façade of African Pavilion in Expo 2008 (Bambó y Azcárate, Zaragoza, Spain), the wind would activate swinging panels with mirrored surfaces that reflected the moving environment.

Furthermore, the reflected image depends on the relative position of the observer and the lighting. If the observer moves, the image will change accordingly to the movement, in short, 
they are mutually dependent. If light conditions vary, especially the difference in light intensity between interior and exterior spaces, reflection's direction may change to either the exterior or internal face of the façade cladding. A reflection's sharpness may also be altered depending on a major or minor level of transparency of the material. The expressive possibilities of this plastic resource are immense and Jean Nouvel is probably one of the architects who makes the most of this.

\section{COLORS IN TRANSFORMABLE OBJECTS}

Sometimes the most relevant colors of a building lie over isolated elements that can be easily removed. These color accents characterize the whole space composition, something very common in minimalist or high tech architecture, where there is a neutral background with few colored objects. The building itself has motionless colors whilst the color transformation is carried away by the mobile elements. It is possible to color a public space just with the dyed clothing of the visitors. It could be the works of art that transform the color of an interior space (e.g. Kirchner Museum, arch. Gigon \& Guyer, Davos, Switzerland, 1992), or the furniture of a room whose colors were not previously defined (e.g. Farnsworth house, Mies Van der Rohe, Plano, Illinois, 1951).

In these designs color is coincidental, as a consequence of circumstances beyond the reach of the architect's preconceptions. It is a color transformation based on omission, which assumes unscheduled changes and allows a multiple reality to contaminate using multiple colors. Occasionally the architect forces there to be a variety of colors in such a way that the final composition is not entirely dependent on coincidence, but rather anticipates a range of colors that are expected to occur. This happen in some stadium seating with random shades that express the irregular and lively colors of the public seated when the venue is full of people (e.g. Lasesarre Stadium, Eduardo Arroyo, Barakaldo, Vizcaya, 2003).

\section{MATERIALS WITH TRANSFORMABLE COLORS}

Some building materials have constantly changing colors, or are able to transform over the years. Contemporary architects are more and more interested in these materials with ambiguous colors, which show evidence of their ageing. They often involve microscopically induced surface effects that imitate the fragmentation of luminous waves seen in fish scales and butterfly wings. As Jean Philippe Lenclos points out, "we now celebrate the unexpected and the mysterious - found in nacreous effects such as color shift, optical interference, iridescence and pearlescence, etc." 7

Amongst the metallic materials with changing colors, the most outstanding are copper, steel and titanium. While oxidation occurs, copper changes from reddish through whitish to turquoise (e.g. Nemo Investigation Centre, Renzo Piano, Amsterdam, 1997). It has been historically used in building's roofs because of its malleability and easy adaptation to irregular geometric joints.

Weathered Corten steel turns reddish when it deteriorates. This material has gained prominence in projects involving work on architectural heritage sites, probably because of its rusted patina, which evokes the passing of time, and a warm and suggestive language. Corten steel provides different hues as a consequence of unequal deteriorating processes (e.g. Archeological park-museum of Kalkriese, Gigon \& Guyer, Germany, 1998-2001).

The use of titanium, with a natural grey finish, has gained popularity through the architectural projects of Frank Gehry (e.g. Guggenheim Museum, Bilbao, Spain, 1997). The metallic reflections suggest a continuous transformation of his organic shapes through the course of the day. Titanium may change its color via an anodizing process, comprising a fluctuating electric potential. However, we have been unable to find a building that implements this particular material on a large scale.

Amongst the paintings with color transformation capacity, we find paintings which add metallic reflections to the color; dichroic paintings that change the hue depending on the angle of light and observer; and phosphorescent paintings, which transform ultraviolet into visible light and seem to emit their own brightness. Even nowadays when the evolution of these paintings in the industrial field has reached a certain level of importance, their application in buildings is being slower and more gradual. Architect Nial Mc Laughlin ${ }^{8}$ displays a material with dichroic 
properties in the Peabody Housing façades (Figure 3): "At times the light effect is robustly geometric; at others it is evanescent and fugitive. Our aim is to create a dreamlike quality, though the image of the façade will not be completely fixed in the mind. In other words, we want to connect our building with the shifting, uncertain and fugitive properties of this place".

Figure 3. Peabody Housing, Nial Mc Laughlin, London, 2002. Photo by Steve Cadman in http://www.flickr.com/photos/stevecadman/2362040196/

Amongst poured materials, of particular note is pigmented concrete, due to its hue variation over the course of the years, perfectly integrated in its texture and physical aspect. As years go by, color loses its homogeneity and chromaticity, showing the scars inflicted by time.

For the extension in the museum for the "Am Römerholz" collection by Oscar Reinhart (Figure 4), copper and sand dust are introduced into the prefabricated concrete panels in order to intensify their color as oxidation takes place. This is the opposite to the common tendency for the loss of chromaticity and brightness through the years: "The combination of limestone and copper powders contributes to quick-acting oxidation and, as such, to a green shift in the coloration of the concrete slabs. As the roof water is enriched by copper ions over time the process of the façade turning even greener will be intensified. By virtue of this accelerated patinization, the new building will undergo an alchemical adaptation and make a kind of journey through time towards the genius loci of the two older, historicizing elements",

Figure 4. Museum for the Am Römerholz collection from Oscar Reinhart, Gigon \& Guyer, 1998. Photo by Siebensachen in http://www.flickr.com/photos/siebensachen/5359851961/sizes/m/in/photostream/

Sometimes the deteriorating processes described are produced artificially. "The second approach is to literally attack the surface of the Wall - with tools that scratch, score, scrape, gouge or chisel (...). Burning represents another dimension of our surface attack, when blowtorches are used to scorch, char and blister the wall"10.

When using stained glass, the versatility of color may be achieved arranging images with a wide range of hues and color gradients over them. The identification of the colors is difficult when these glass surfaces are superimposed over other materials, producing an effect of constant transformation. French Artist Yves Charnay" ${ }^{11}$ uses "silk-screen printings on polycarbonate sheets and on glass. These works are positioned like stained glass in front of building openings (...) in two or three coats. This feature influences the color mixture. The color of these works varies with the position of the spectator." A theatric and dramatic result is achieved, like in the Department Store Gallery in Seoul (Figure 5), which is clad with glass sheets treated with a special iridescent foil. The façade shimmers in all the colors of the rainbow.

Figure 5. Department store gallery, Ben van Berkel, UNStudio, Seoul, 2004. Photo by gTunes in http://www.flickr.com/photos/giselegass/1592178055/

\section{TRANSFORMATION DUE TO LIMITATIONS OF THE OBSERVER}

Some buildings seem to transform even when neither light conditions, nor the object have changed. This happens in compositions where color is complex and difficult to apprehend (e.g. offices "La Defense", Ben van Berkel, Almere, Holland, 2004). The building as a whole, results unstable and the observer perceives a different view each time. In general, we refer to architectures that use plenty of small colored fragments that do not respond to easy understanding composition orders (Figure 6).

Figure 6. Spanish Pavilion in Expo Aichi, Alejandro Zaera Polo, Japan, 2005. Photo by Kimo Toyama in http://www.flickr.com/photos/kimo/43673450/

Color instability can also arise from a contradiction between the building and its real geometry. "It seems possible to dissolve the laws of perspective by using areas of color in a space where color and tonality develop their own depths. The interplay of these forces generates a new type of space in which optical and physical space virtually oscillates, the type of space that calls into question both expectations and habitual ways of looking at things. If you 
join this game as a viewer, you have to make your own experience: looking at things in a conventional way is not longer enough, you have to understand space with your own intellect and fantasy, with your whole body"it2.

\section{COLOR FRAGMENTATION. CHANGES IN THE INTEGRITY}

Versatility may suggest a change in architecture's integrity and involve its fragmentation. This concept in contemporary architecture is related to fragmentation in sociology, introduced by the German sociologist Ulrich Beck, who "points out that the sources of collective and specific group significance (as for example the faith deposited on human progress and class conscience), usual in the industrial society, are in crisis and becoming disenchanted (...). Consequences are the loss of human significance and, even more, the lack of human's structuring capacity. In this last sense, Fredric Jameson (1991) underlines that while modern society's characteristics are anguish and hysteria, postmodernist society is based on the fragmentation and the schizoid (...). Human nature's cultural forms have, nowadays, disappeared (nuclear family, extended family, traditional groups, etc.), and with them, any possibility of assuming prefixed behavioral rules, which could avoid anxiety when facing uncertainty"13.

To seek fragmentation involves understanding the architectural project as something disperse and contradictory, and to renounce to shape monolithic or unitary objects. The building results in a kind of totality, in which the alien origin of its components can be tracked. Fragmented architecture usually has complex color dispositions that reinforce the idea of a hybrid reality based on disperse remnants. This new design process requires new expressive mechanisms such as the collage or the panographies which have been used in the twentieth century (cubists, Dadaists, surrealists, etc).

Moreover, since Le Corbusier and P. Jeanneret put forward their "Five points of modern architecture" (1962), a building's envelope (façades and roof) may be detached from the structure. This structural independence allows façades to become the expressive component in architecture, understood to be the $\operatorname{skin}^{14}$ that hides the supporting skeleton beneath. Architecture's beauty does not necessarily depend on coherence between form and construction but rather on what covers it.

Contemporary color goes through this double fragmentation process whereby it is disassociated from the structural aspect of the building while at the same time emphasizing the break-down, dispersion or conflict between the parts.

\section{FRAGMENTATION BETWEEN STRUCTURE AND FINISH}

Those critics who have tracked the evolution of the independence between surface finish (color) and structure in architecture usually start the discussion quoting architect Gottfried Semper (1803-1879), who was opposed to the illustrated thinking of historian Wincklemann or Philosopher Schopenhauer (Sauerbruch and Hutton, 2006; Paczowski, 2001; Wigley, 1995).

Schopenhauer, an unconditional defender of classicism in architecture, studied the difference between those surfaces which define a building's shape, and those that support it. Architecture is described by Schopenhauer (1844) as the art of overcoming gravity with the collection of supported and supporting elements. Spatial properties have had a secondary origin in architecture as its "unique and constant theme was to support and sustain". Buildings which hide their structure make him anxious as "we cannot see what supports them: they seem to float in mid-air and disturb the spirit of the passer-by"15.

A few years later (1845), architect Karl Bötticher, passionate about Greek architecture and Professor of the University of Architecture in Berlin, established the distinction between Werkform (structural form) and Kunstform (artistic form) resulting in a conflict between artists and architects in the Deutscher Werkbund's. Bötticher understands, as Semper does and opposing Schopenhauer, that the interest in Greek architecture lays in its expressive exterior layer (Kunstform) which makes the building visible, and not so much in its structural character (Werkform). The elements in a Greek temple not only play their specific constructive function but also a symbolic and idealistic one ${ }^{16}$.

Following on from this distinction, Semper states that the interesting point in architecture is to study how to hide the methods used to reach an artistic result, although this simulation 
cannot be successful if behind the mask, the shapes are not well arranged ${ }^{17}$. From its earliest beginnings, and in Semper's opinion, the primitive hut made out of cloth was a place for celebration and decoration. The first human structures were temporary scaffolding, covered with cloth or fabrics for the celebration of religious or civic events. Scaffolding was just the support needed for another objective: the symbolic and representative character of architecture.

Semper assigns color in architecture not only as a protective function for the constructive material, but also a symbolic one, by means of which the most mysterious religious concepts can be expressed ${ }^{18}$. When architecture evolved becoming more solid, the painted layer is the continuation of this textile tradition as a "material transfer" (Stoffwechsel) thanks to which space is composed. The supporting elements are hidden as the real iconology lies in color. Semper is more interested in architecture's surface captivation than in shaping. Mark Wigley states that Semper's "visuality is tangled-up with sensuality" ${ }^{\prime 19}$. When he visited the International Exhibition in London in 1851, Semper was fascinated with the colored fiber walls of the Caribbean hut. This is a possible explanation of the appearance of Semper's ornaments on the walls of his buildings, which look like rich tapestries ${ }^{20}$. Semper (1985) considers color to be "the most subtle way to dress a body... the best way to finish the reality"21.

During the twentieth century, the disconnection between shape and material finish has remained in many of the avant-garde artistic movements, such as Russian constructivism. "Lissitzsky and later Theo van Doesburg sought in vain to challenge the architectural dictatorship of the spatial form and its materiality by using color to deny or alter the basic form of the interior spaces and volume. Here the color seems to have become an ideological signboard, a doomed painted revolt against the primacy of material and spatial form"22. Color's interpretation of the Proun acquires a connotation which exceeds its composite intentions.

Other architects from the modern period such as Le Corbusier, are reluctant to accept the wall as a simple support for the artistic layer."I reject the wall to become a tapestry, and the architect an upholsterer. (...) Reject the colors that can be qualified as non-architectural, better than that, make a research and choose those colors that can eminently be called architectural, and restrict to them, and say ourselves: it's enough with these!"23.German architect Bruno Taut, like Le Corbusier, differentiates between being a painter and an architect, giving priority to the latter: "The painter I have in me is subordinated to the architect. For me, painting can never be a main aim"24. Taut also warns of the danger of multi-colored provisions: "the pure and bright colors are wonderful, but wrongly applied, they are much worse than the absence of color. (...) Bright colors together are not yet any color, in the same way that loud sounds all together don't compound a melody" ${ }^{\prime 25}$. But do not be misled; the German architect is a strong advocate of bold color compositions, especially in urban areas, where he ensures that "mid-terms" are not desirable. Taut's color "purity" does not oppose a great creative freedom, and certainly, it is far from Le Corbusier's rigid purism or the narrow range of hues of the neoplasticists. Neoplasticists call for a symbiosis between disciplines, painting and architecture, and position in favor of none. Both need and complement each other as "the painting detached from architecture (canvas) no longer has any right to exist"26. Dutch painter Bart van der Leck (1876-1958) states: "If architects look for a painter who can find the desired image, then the modern painter looks for an architect who can provide appropriate conditions for a truly perfect union of visual plastic expression" ${ }^{27}$.

In the sixties, Venturi and Scott Brown claimed to recover the plastic and communicative effects in architecture, going beyond the "simple" and "clear" shapes of the functional school ${ }^{28}$. The unity between external form and structure, paradigm of the modern movement in architecture, is put into crisis in favor of meaning or content. This crisis is illustrated in two basic architectural types: the "duck architecture", in which the commercial and figurative message deforms the spatial and functional structure; and the "decorated template" consisting in a functional box which has been decorated according to its use, but not taking into account its spatial structure.

Nowadays, there are many buildings conceived as mere supports of a certain superficial color composition; however, there are few architects that recognize a color "decorative" conception. Probably, Adolf Loos' influence is too extensive and leads to this color-ornamental rejection: "Color must be at one with the building; working directly on the building's surface or the intended building material is the only way; it implies a different contemplation that allows one to avoid an isolated or decorative intervention"29. Mattias Sauerbruch assures that there is still this prejudice "'against the literal superficiality of the application of color onto a surface. This is coupled with color's physical instability, such that the ensuing ephemerality of the surface is seen to undermine the serious and enduring solidity - both literal and metaphorical - of the 
volume. So the colored surface was - and is - perceived as subordinated to the white body (there being the assumption that if the form is not colored, it can only be white)"..$^{30}$ In the Experimental Factory (Magdeburg, Germany, 1998), these architects design a great roofblanket that shelters all the laboratory activities. This roof-blanket, according to Semper's way of thinking embodies all the expressive and symbolic power of the building.

\section{FRAGMENTED COMPOSITION SYSTEMS}

In view of the fragmented, controversial and disperse reality, some architecture renounces the creation of unitary and autonomous objects. It only aspires to establish a certain balance between segments with a different nature. This architectural design understanding deals with complexity and diversity. We refer to crossbreeding architectures, where the concerns of the project (formal, economic, social and structural), collide and mix one with another in a delicate balance.

We are talking about architects more interested in the process used to obtain the shape, rather than in the final formal result. Strictly speaking, we are not talking about an architectonic object, as contemporary composition systems are not even object-based; they display open designing processes that do define a working mechanism but do not anticipate a final result which is, at first, unpredictable.

Architect and critic J.M. Montaner describes two opposite trends towards fragmentation's evolution: “(...) On one side, the articulation of parts in a new coherent result based on superimposition and interaction trying to group the fragments into mega-objects and massive buildings, and on the other, the irretrievable dispersion of fragments into autonomous and unconnected pieces ${ }^{\prime 31}$. Regardless of the composition method used to express fragmentation, it is usual for color to distinguish and separate the fragments, underlining their different origins and characteristics. Color is a code that informs the observer about the specific internal logics of each fragment: different use, different character or different constructive system.

This is the case with the Silodam Building (Figure 7), a huge rectangular abstract prism, the result of adding smaller pieces together, each belonging to a variety of different building types. "It became a container of houses, literally interpreting the surrounding harbor. Adding a 21 st-century silo of houses to the adjacent $19^{\text {th }}$ and $20^{\text {th }}$ century silos., ${ }^{32}$

Figure 7. Silodam Building, MVRDV architects, Borneo, Amsterdam, 2002. Photo by Lauren Manning in <http://www.flickr.com/photos/laurenmanning/>

As mentioned before, Le Corbusier uses color to combat fragmentation, which he is strongly opposed to. Not only does he want to take a step back from his neoplastic colleagues, but he also wants to establish an easily recognizable rational order. In Les quartiers modernes frugès (Pèssac, France, 1924-1926) color is used to organize some "groups of eight houses that give the impression of being too turbulent, violent, bristled, too sculpted", in a way that "the diverse elements speak one after the other and without ambiguity, through color" ${ }^{33}$. Color enables Le Corbusier to establish a strict control over each of the elements that compose architecture. $^{34}$

Contemporary architecture in general, with the exception of some minimalistic trends, does not aim to achieve the unity that was usual in modern architecture. Nowadays, fragmentation is aimed to be used as an expression of freedom, against monolithic interpretations of reality and, moreover, an escape from the boredom that stems from monotony ${ }^{35}$.

\section{COLOR MOVEMENT. CHANGES IN POSITION}

With the industrial revolution and the development of different modes of transport, movement is identified as part of a new culture, based on the success of both reason and scientific understanding. Art then sets out on a challenging pursuit to express this variable, which is linked to a new life-understanding.

Cubist painters try to capture dynamism superimposing various visions of the very same object taken from different points of view. Painting is freed from the traditional perspective and tries to better express the object as a whole. The futurist paintings by Giacommo Balla (1871- 
1958) or Umberto Boccioni's sculptures (1882-1916) try to capture the kinetic sense of reality. Even Marcel Duchamp (1887-1968) was interested in movement in his painting, with consecutive superimposed images, similar to stroboscopic photography, matching cubist and futurist elements (e.g. Nude descending a staircase, Marcel Duchamp, oil on canvas, 1911). The samples are numerous and continue through to the present day, although some art critics point out that these avant-garde offerings were always "in the rear". "A camera on rails can express velocity better than a futurist Balla painting can. (...) Avant-gardes refused to accept this situation until the triumph of the modern consumer society, in the fifties, and after admitting the latter, the avant-garde movement can no longer be justified" ${ }^{\prime \prime 6}$.

In modern architecture, movement is related to machines, to mechanic devices. Italian architect Antonio de St' Elia (1888-1916) imagined a futurist city based on high-speed transport vehicles such as trains, etc. Even Le Corbusier describes his buildings as machines for living ${ }^{37}$ and creates the Promenade architecturale, which is a kinetic experience of space by means of a journey. This leads to the designing of itineraries that include corridors and ramps. "A ramp trajectory allows a continuous perception, maintaining vision fixed on an attractive object (...) If we want to find out the shape of any of his buildings [by Le Corbusier], we must identify the door and ramp element, because 'architecture' happens in this trajectory" ${ }^{\prime 3}$.

Some of the utopian artistic trends during the sixties envisioned a future nomadic society where movement is implicit in its way of life. According to Archigram (1960), humanity has to travel from one place to another due to environmental disasters, whilst the Situationist International (1957) incorporates the erratic movement of people. In New Babylon (Constant Anton Nieuwenhuys, 1969), drifting aimlessly becomes a creative action termed dérive, that is presented as an alternative to obsolete and simple urbanism of the modern period. The opportunity to play, throughout movement, may increase the potential of an oppressive city that is aiming to be more anarchic.

Some contemporary architects work with lines of movement, which are understood to be flowing energy. As to the Vitra Fire Station (Weil am Rhein, Germany, 1993), Zaha Hadid points out that "the whole building is movement, frozen. It expresses the tension of being on call and the potential of bursting into action at any moment ${ }^{\text {"39 }}$.

\section{MOVEMENT WITH STATIC COLORS}

Movement can be suggested without a real displacement between the observer and the architecture, and colors alone can modify the perception of depth. The use of small and contrasted colored patterns may generate relative movements between the different colors, so that the shape would seem to dissolve. This is a mere perceptive phenomenon and has undergone in-depth research by Op Art movement artists such as Victor Vasarely (1908-1997) and Bridget Riley (1931-), amongst others. When small pieces of color dots or strips are put together, pieces sometimes seem to move; their edges fade and become blurred; their surfaces seem to vibrate, constantly changing (e.g. The Brandhorst collection museum, Sauerbruch Hutton, Munich, 2002-2007).

Color movement in architecture has traditionally been understood in a musical sense. Architecture movement is the rhythm, the distribution of silence and accents visually perceived, which break with static's monotony. Color allows the introduction of this rhythm in architecture, a particular cadenza. Such is the case of the T4 terminal of Barajas airport (R. Rogers and Lamela, Madrid, 2006), where the rainbow color range gives rhythm to an extremely extensive and monotonous succession of identical structural supports.

\section{MOVING COLORS}

Architecture's versatility may be expressed by mobile colored elements in the buildings which are triggered manually or mechanically, by weathering, etc. Cases are numerous, like the emblematic Schröeder house (G.T. Rietveld, Utrech, 1924), with colored mobile partitions that permit variations in the inner space configuration so that it can be adapted to different needs. The dwelling's partitions are abstract planes and independent from the rest of the building, an abstraction reinforced by the use of non-natural colors, though using pure and homogeneous shades. 
It has already been mentioned how Venturi and Scott Brown call for the recuperation of communicative plastic effects in buildings, based on an analysis of the "Main Street" of some American cities, with plenty of ads for the passer-by. "This exaltation of significant architectures carrying messages and with superimposed masks, open the door to a new attitude which opposes ascetism and the restraint of the modern era. (...) A figurative architecture which moves away from the abstract and represents other aspects from those concerning the functional ones" ${ }^{\prime \prime 0}$. There are emblematic urban spaces with just this characteristic colors in motion: Times Square in New York, downtown Tokyo, Las Vegas, Piccadilly Circus in London, etc. These are places where information, publicity and show headliners are blended together in a continuous color-changing façade. This postmodern city has undoubtedly come about as a result of the development of artificial lighting, the advent of huge television screens as well as large scale projection systems. Haeusler ${ }^{41}$ distinguishes between simply light architecture and media architecture, which contains dynamic text, graphics or images. Looking at the different methods of displaying content, we can differentiate between: "mechanical facades, projection facades, rear projection facades, illuminated facades, window raster animation, display facades and voxel façade systems". Attending to the visual text of the screens, Simone Arcagni describes four different kind of media facade: "advertising, network and broadcast, media events/ live media events, and information" ${ }^{\text {, }}$.

The Tower of light (Toyo Ito, TL Yamagiwa Laboratory, 1986, Yokohama, Japan) is one of the first examples of computer controlled lighting. "The lamps are programmed in a way that the neon rings light up to approximately mark the hour; the light of reflectors on the ground changes in intensity depending on the wind's direction and speed and the mini-lamps light up, tracing in real time different designs as an interpretation of the surrounding environment". ${ }^{3}$ There are many other outstanding examples such as the Kunsthaus in Graz (Figure 8) with a matrix of fluorescent light tubes, like "big pixels" that screens films and animations, or the façade of the Haus des Lehrers (Chaos Computer Club, Berlin, September 11, 2001) which was turned into an interactive computer display, where participants were able to change the windows lighting by calling a telephone number.

Figure 8. Kunsthaus Graz; Peter Cook, Spacelab UK and Colin Fournier; Graz, Austria, 2003. Photo by "simsitem" in http://www.flickr.com/photos/simsitem/387046650/in/photostream/

\section{COLOR NOVELTY. CHANGES IN PROCEDURE AND TECHNOLOGY}

One of the obsessions of the avant-garde movements when trying to express the spirit of the new era was to experiment with all possible expressive and technological resources. All these possibilities should be exhausted and art was established as a continuous experimental laboratory. There was a special interest shown in the artistic value of novelty, which leaded to the use of a variety of original procedures. "The history of the visual avant-gardes from the twentieth century is the fight against technological obsolescence". ${ }^{44}$

Architecture has a great inertia towards technological innovations. The need for buildings to last, added to economic restrictions, requires the correct verification of new procedures and construction materials. Generally, fewer risks are assumed and new features are slowly introduced. Of course coloration systems are tested by means of experimental prototypes and laboratory buildings. In addition to the availability of the new colored materials, there has been a profound evolution in design tools thanks to computer developments, which have influenced color's nature and composition.

\section{NOVELTY IN COLOR'S NATURE}

Some architects consider increasing chromatic intensity in architecture as a response to the aspiration of approximating a building's image to the one presented by through digital technology. Koolhaas describes our contemporary experience as over-stimulated, since physical reality has been heightened through technology. "It is only logical that, with the incredible sensorial onslaught that bombards us every day and the artificial intensities that we encounter in the virtual world, the nature of color should change, (...) all potentially enhanced and therefore more intense, more fantastic, more glamorous than any real color on a real surface" ${ }^{\prime 5}$. Moreover, their limits could even fade making us confuse fiction and reality; such is technology's influence over our perception. "Color in the real world looks increasingly unreal, 
drained. Color in virtual space is luminous, therefore irresistible. A surfeit of reality-TV has made us into amateur guards monitoring a Junkuniverse... (...) Conceptually, each monitor, each TV screen is a substitute for a window; real life is inside, while cyberspace has become the great outdoors... (...) The cosmetic is the new cosmic..."46

Zaha Hadid expresses herself in a similar way when she states her preference for digital images rather than printed ones: "I think it is much nicer on the screen that when it is printed onto paper, because the screen gives you luminosity and the paper does not, unless you do it through a painting" ${ }^{\prime \prime 7}$. Her sketches are drawn on black backgrounds. This way, the colors displayed seem to shine with their own light source, as if we were looking at a computer screen.

Cad software usually works with layers, which allow different, simultaneous drawings to be superimposed or hidden at will. Usually, theses layers are assigned their own identifying color, in an architecture which is still being shaped. It is a color code, used to identify unmistakably and without confusion. Michael Riedjijk ${ }^{48}$ points out that color are associated to certain meanings, as a consequence of using computers. "Color codes are like an aura of the building to come, voluptuous red for intimacy, cobalt blue for a sublime detachment, (...) Color is a code in a world of thoughts and evocations which may at some time have to become a reality of brick, concrete, steel, wood and glass".

Color's nature seems to evolve from the material to the immaterial, from pigmented color to light color. Whigley assures us that "the new architecture of color understands light as a material. So architects are not saying they make an object and then position the light on the object, but rather they are shaping light." Wigley considers the future, or the immediate present, to be very encouraging. "We are going through an incredibly interesting moment in the control of color and creativity with color, and interactivity with color will go from being a sign of make-up or seduction and will be truly understood to be a structure. And also it is an electronic structure; because of course we can't easily distinguish the world of electronics from the world of material. Color is blurring this relationship",49.

\section{NOVELTY IN COLOR'S COMPOSITION}

The development of computing applications has notably influenced color's composition. The potential of media-façades that leave the design unfinished, open to the observer's interaction, has already been discussed. We now pay attention to the most elementary concept of digital color: the pixel, defined as the smallest unit of an image on a television or computer screen.

Pixilation as a compositional system involves an abstraction process, the reduction of an image to its essential range of colors, something that is easily achieved using software. In other occasions, pixilation consists in enlarging an image until it becomes just a sequence of shades, which are laid over the building. This fragment of an enlarged image corresponds to an unknown whole for the observer.

This resource has been employed by Emilio Tuñón Álvarez and Luis Moreno Mansilla at the Contemporary Art Museum in León (Figure 9), in which colored stained-glasses are reminiscent of the imposing stained-glass windows of the city's gothic cathedral. In this case, as in some others (e.g. Santa Caterina's Market, Enric Miralles and Benedetta Tagliabue, Barcelona, 2003), if the picture references were perceived in a more naturalistic way, we could talk about color composition as a big picture that identifies the use of the building or its relation with the architectural heritage. However, this relation is difficult to monitor, and we may say that color is virtual, because it has nothing to do with the building shape but with its appearance.

Figure 9. Contemporary art Museum in León, Emilio Tuñón y Luis Moreno Mansilla, León, Spain, 20012004. Photo by Luis Angel in http://www.flickr.com/photos/luisangel/116313051/

The pixel is not only a basic unit of color; it also involves an indivisible and elementary information unit. With this approach, the Spanish architect Eduardo Arroyo develops his project for El Desierto square (Figure 10). The design of this public space is the result of a random distribution of pixels that result in a diversity of finishing materials. Pixilation is an open designing strategy that allows infinite results, a versatile designing process.

Other times, computers generate very abstract virtual colors and three dimensional shapes. The artificiality of some built environments looks like a literal translation of an image 
rendered by a computer (e.g. Hageneiland dwellings, MVRDV, Ypenburg Den Haag, The Hague, Netherlands, 1997-2001).

Figure 10. El Desierto Square, Eduardo Arroyo: Nomad, Barakaldo, Vizcaya, Spain, 1999. Photo by Roland Albe and Geraldine Bruneel in http://www.landezine.com/index.php/2009/07/plaza-del-desierto/

\section{CONCLUSIONS}

Color in contemporary architecture is a useful resource to express versatility, an aspiration inherited from the modern era that is based on four potentials for change: transformation, changes in the visual aspect of the buildings; fragmentation, changes in the integrity of the buildings; movement, changes in position; and novelty, changes in procedure and technology.

Color transformation may be achieved through changes in the light source, incorporating reflections, the use of transformable materials and colors, or as a consequence of the observer's limitations, to name but a few.

Color may alter architecture's integrity and result in its fragmentation. The notion of fragmentation is shared by both sociologists and some contemporary architects, who understand reality and architectonic projects to be dispersed and contradictory phenomena. This has been possible due to the detachment between finishing materials and the architectonic structure, and to fragmented composition systems, amongst others.

The interest in movement expression in arts has its roots in the early avant-garde. Contemporary architecture employs either static colors that suggest movement or colors that do actually move.

Color novelty or the change in technology and coloration procedures, involves the experimentation of every possible technological and expressive method. This is the obsession from the early twentieth century of expressing the spirit of the new era. Computer-aided color has acquired a huge prominence in this sense, greatly expanding the creative potential. This fact has influenced both the nature and composition of color.

The pursuit of these four concepts, namely transformation, fragmentation, movement and novelty, may explain the way in which colors are conceived and arranged in much contemporary architecture. In this way, we aim to re-establish the importance of color in architectural design, overcoming earlier theoretical and practical prejudices stemming from the modern era.

Nevertheless, the future of color in architecture should focus not just on the versatility of an isolated building, but on the relationships between color and the environment, something that common computer programs are currently still unable to easily do. Perhaps in this way, the autism of certain contemporary color arrangements could be overcome, as well as the predicament of certain buildings that are understood to be isolated objects or out-of-context artifacts.

1. Riedijk, M. (2009). Code, space and light. In T. Porter, et al. (Ed.), Color for architecture today. (p. 106). London: Taylor \& Francis. Pag. 108

2 University of Cambridge (1995). Cambridge international dictionary of English. Cambridge: Cambridge University Press.

3 Montaner, J. M. (1999). Arquitectura y crítica. Barcelona: Gustavo Gili

4 Aguilar Rico, M. (1981). Física del color. Valencia: Universidad de Valencia, Instituto de Ciencias de la Educación.

5 Le Corbusier (1923). Hacia una arquitectura. Barcelona: Apóstrofe, 1998.

6 Bony, A. (2009). Evoking a response. In T. Porter, et al. (Ed.), Color for architecture today. (p. 87). London: Taylor \& Francis. (2009: p 91),

7 Lenclos, J. (2009). The geography of color. In T. Porter, et al. (Ed.), Color for architecture today. (p. 39). London: Taylor \& Francis. Pag. 86

8 McLaughlin, N. (2009). The illusive façade. In T. Porter, et al. (Ed.), Color for architecture today. (p. 109). London: Taylor \& Francis. 
9 Gigon \& Guyer in Schindler, V. M. (2007). Colored Surfaces - Architecture's Expanded Field: An Inquiry into Color Application in Switzerland's Contemporary Architecture: AIC 2007. Color Science for Industry, p. 215-218.

10 Ibid Bony P. 91

11 Charnay, Y. (2010). Works of Light integrated into architecture. Light, color and architectural expression. In Zennaro P. (Ed.). Color \& Light in Architecture. (p. 149-153) Venice: Università luav.

12 Sauerbruch, M. and Hutton, L. (2006). Sauerbruch Hutton archive. Baden: Lars Müller. P 227

13 Sosa Sánchez, R. P. (2008). Una reflexión sobre la noción de fragmentación en la sociedad de cambio de siglo: Revista de antropología experimental, 8, 397-401. Jaén (Spain): Universidad de Jaén.

14 Baraona Pohl, E. (2007). Piel. Skin. España: Imaginación impresa.

15 Schopengauer in Paczowski B. (2001). Couleur, peau et structure [Online].

16 Mallgrave, H. F. (2005). Modern architectural theory: a historical survey, 1673-1968. Cambridge: Cambridge University Press. P 513

17 Semper, G. (1860). Style in the technical and tectonic Arts. Los Ángeles: Getty Research Institute, 2004.

18 Nerdinger, W., Oechslin, W. and Semper, G. (2003). Gottfried Semper 1803-1879: architektur und wissenschaft. Zürich: Prestel.

19 Wigley, M. (1995). White walls, designer dresses: the fashioning of modern architecture. Cambridge: MIT Press.

20 (Paczowski, 2001

21 Semper, G. (1985). Der Stil, vol 1, p. 445, cited by Sauerbruch, M. and Hutton, L. (2006). Sauerbruch Hutton archive. Baden: Lars Müller

22 Ibid riedijk $\mathrm{p} 108$

23 Le Corbusier 1923: $p$ 95, 113)

24 Taut, B. (1925b). Renacimiento del Color. Extract from "Farbe am Hause", 1st German Color Congress, Hamburgo. "Bauweltverlag, 1925". In Duettmann, M. (1982). Color en la Arquitectura [Farbe im Stadtbild] (p. 191). Barcelona: Gustavo Gili p 191.

25 Taut, B. (1925). In Taboas Veleiro, T. (1991). El color en arquitectura (p. 177). A Coruña: Edicios do Castro.

26 Mondrian, P. (1930). La morfología y la neoplástica: Circulo y cuadrado, num. 2. In A. González García, et al. (Ed.), Escritos de arte de vanguardia 1900/1945 (p. 270-277). Madrid: Istmo.

27 Der Leck, B. (1918). El lugar de la pintura moderna en la arquitectura: De Stijl, 1918, vol. I, num. 1, p. 2-6. In A. González García, et al. (Ed.), Escritos de arte de vanguardia 1900/1945 (p. 256). Madrid: Istmo.

28 Gössel \& Leuthäuser, 2001

29 Bony, A. (2009). Evoking a response. In T. Porter, et al. (Ed.), Color for architecture today. (p. 87). London: Taylor \& Francis. (2009: p 91), P. 87

30 Sauerbruch and Hutton, 2006: $p$ 182).

31 Montaner, J. M. (2008). Sistemas arquitectónicos contemporáneos. Barcelona: Gustavo Gili.

32 MVRDV (2011). Projects Realized [Online]. In http://www.mvrdv.nl/\#/projects/028silodam

33 Le Corbusier (1931). Polychromie architectural. In Rüegg, A. (Ed.), Le Corbusier farbenklaviaturen von 1931 aund 1950=Le Corbusier's color keyboards from 1931 and 1959=Les claviers de couleurs de Le Corbusier de 1931 et de 1959. Basel: Birkhäuser, 1997. P. 125

34 Carro, R. (2003). Le Corbusier nos hizo el regalo del muro blanco. P 13.

35 Alsop, W. (2009). The color of money (It doesn't matter). In T. Porter, et al. (Ed.), Color for architecture today. (p. 113). London: Taylor \& Francis.

Serra, J. (2010). Colores que alumbran proyectos. Conversando con William Alsop: EGA. Revista de Expresión Gráfica Arquitectónica, 15, 16-25.

36 Hobsbawn, E. J. (1999). A la zaga: decadencia y fracaso de las vanguardias del siglo $X X$. Barcelona: Crítica.

37 Le Corbusier, 1998)

38 Quetglas J. (2011). Promenade Architecturale [Online]. In http://www.arranz.net/web.arch-mag.com/5/homeless/05s.html 
39 Binet, H. (2000). Architecture of Zaha Hadid in photographs. Baden: Lars Müller, p.127

40 Bozal Fernández.

41 Haeusler, M. H. (2009). Media facades: history, technology, content. Ludwigsburg: Avedition. P 12

42 Arcagni, Simone. Media Architectures and Urban Screens as New Media: forms, places and spectatorship. In Zennaro P. (Ed.). Color \& Light in Architecture. (p. 251-255) Venice: Università luav.

43 Haeusler, M. H. (2009). Media facades: history, technology, content. Ludwigsburg: Avedition. P. 26

44 Ibid Hobsbawn, 1999).

45 Koolhaas, R., Foster, N., Mack, G. and Mendini, A. (2001). Colors. Basel etc.: Birkhäuser.p. 12

46 Koolhaas, R. (2002). Junkspace: October, vol. 100, p 175-190. Cambridge: MIT pres. $p$ 189-190

47 Hadid, Z. (2001). Zaha Hadid, 1996-2001: landscape as a plan = el paisaje como planta. Madrid: El Croquis. P.17

$48 \quad$ Ibid Riedijk p. 106

49 Wigley, Mark in Serra, J. (2011b). Color y espacio, teoría y práctica: Reflexiones con Mark Wigley y Mattias Sauerbruch: EGA. Revista de Expresión Gráfica Arquitectónica, 18. P 280-287. 


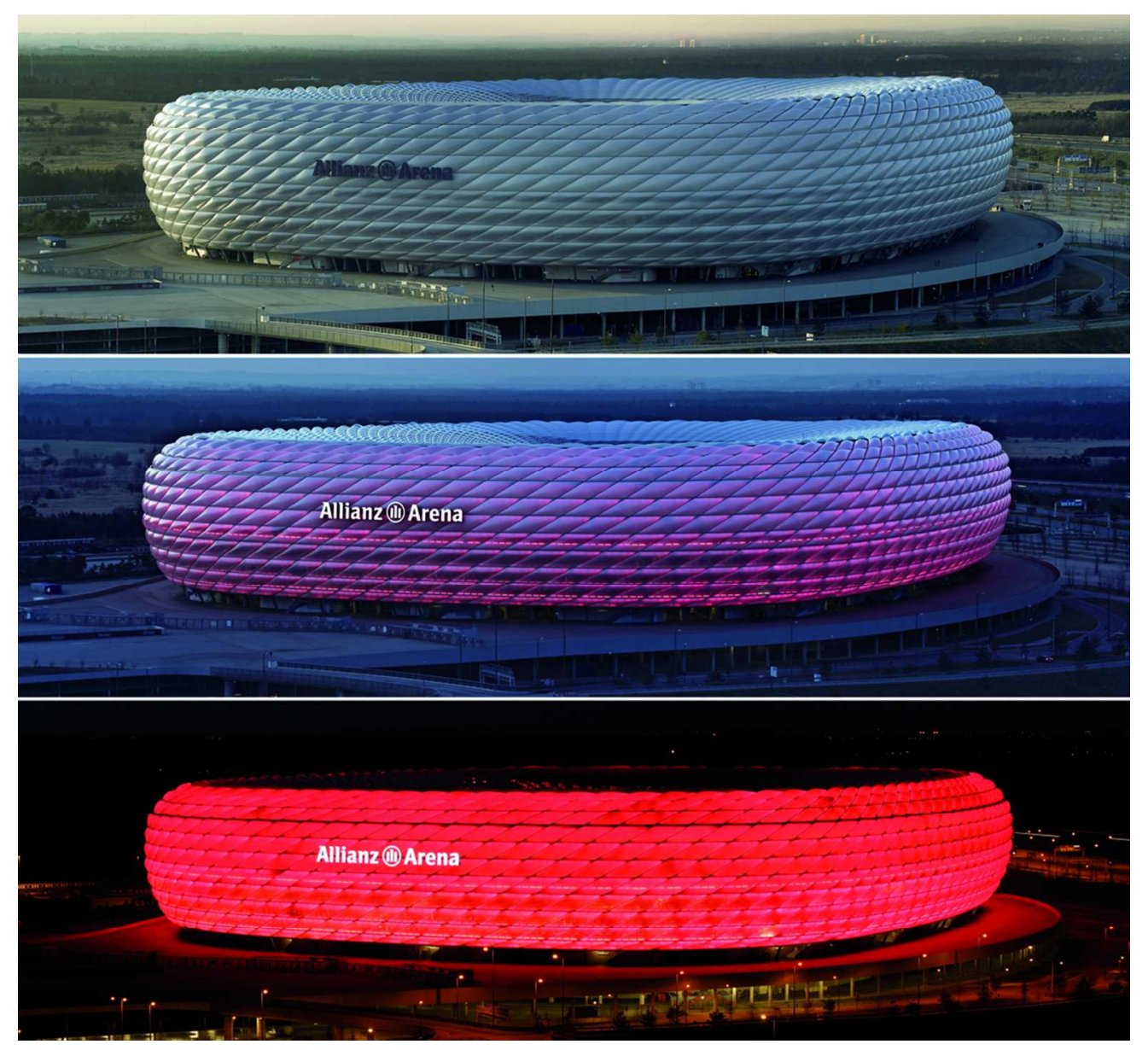

Figure 1. Alianz Arena Stadium, Herzog \& de Meuron, Munich, Germany, 2005. $99 \times 92 \mathrm{~mm}(300 \times 300 \mathrm{DPI})$ 


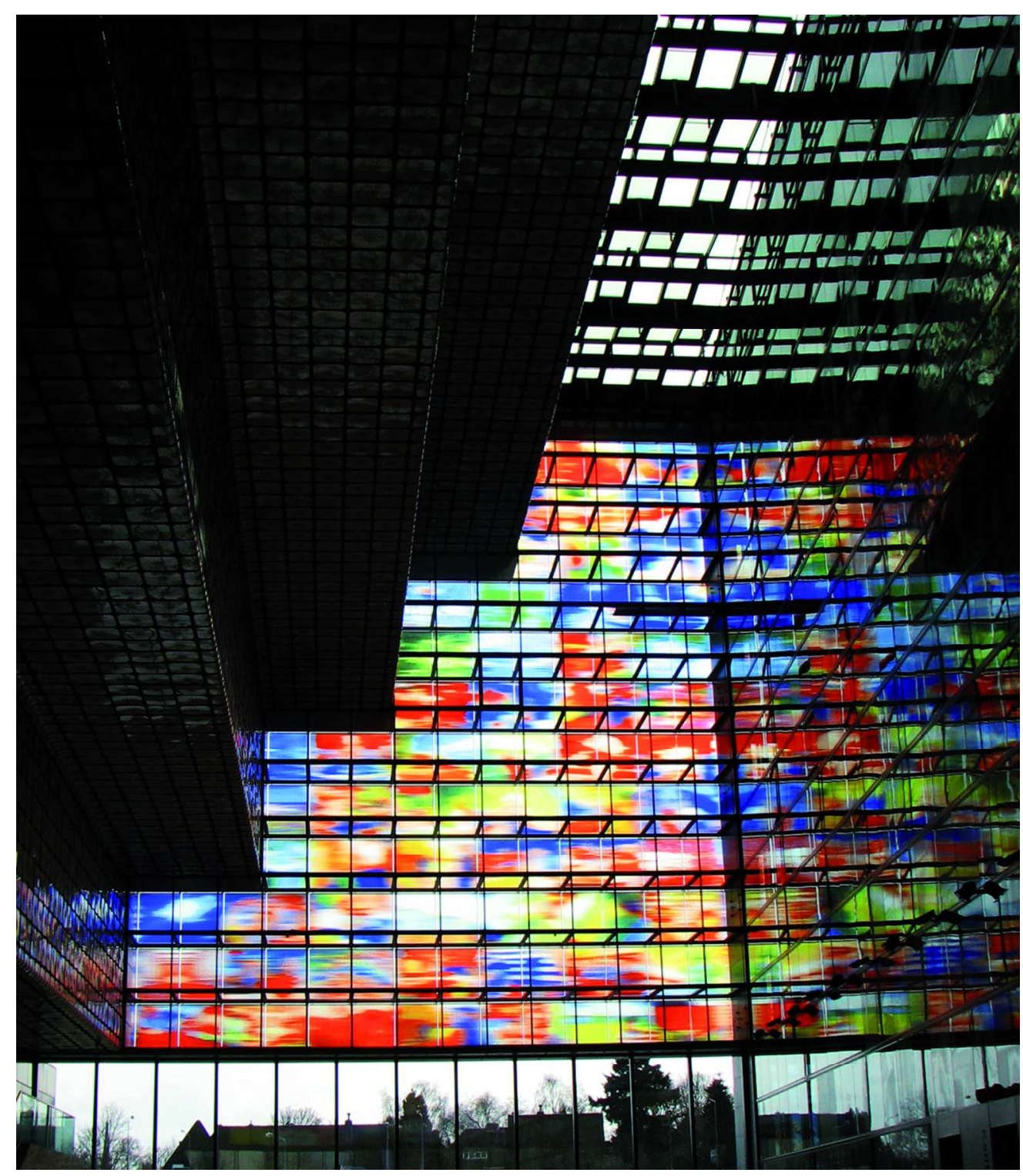

Figure 2. Netherland Institute for Sound and Vision. Neutelings Riedijk Architects, Rotterdam, 2007. $99 \times 115 \mathrm{~mm}(300 \times 300 \mathrm{DPI})$ 


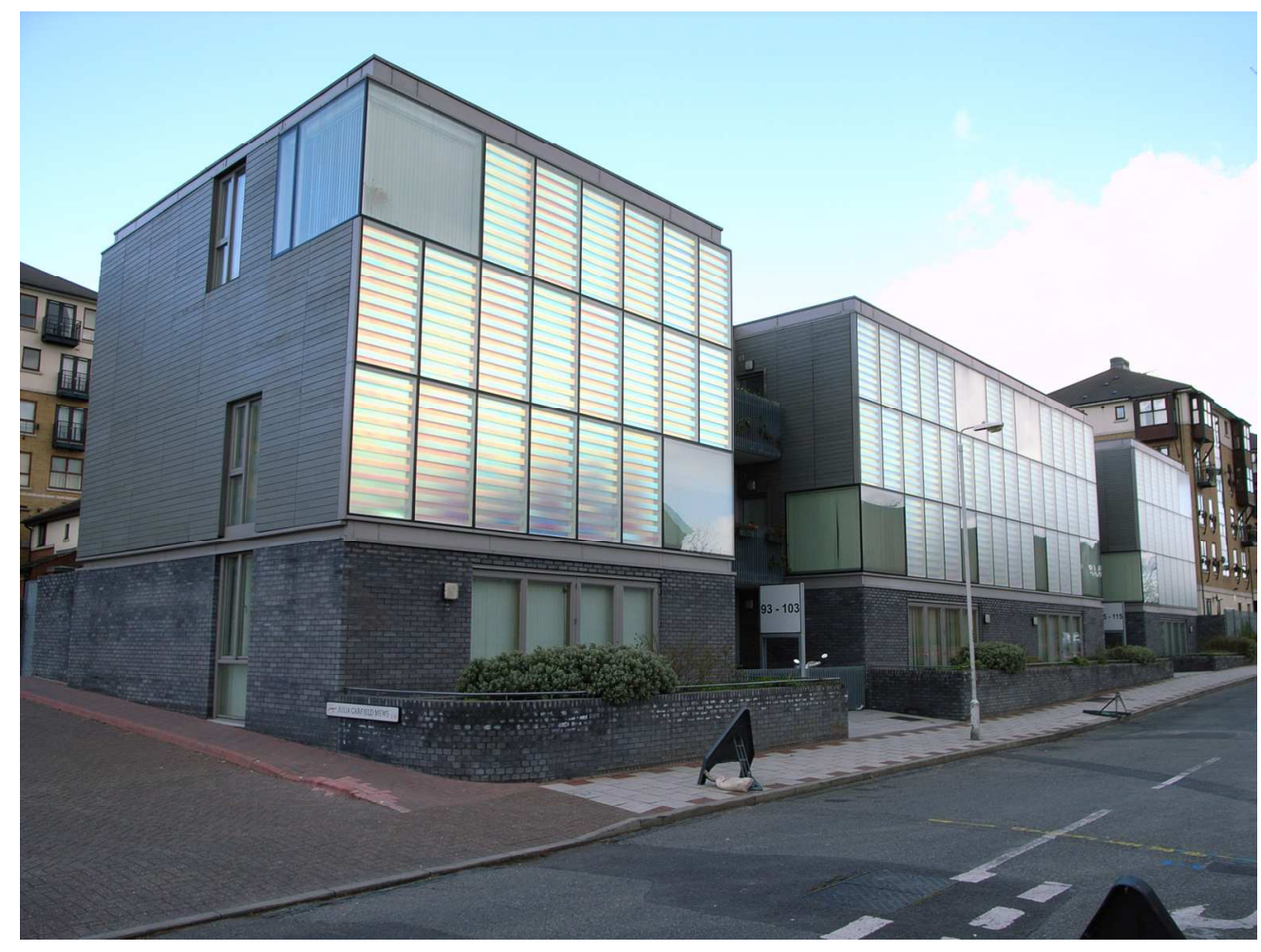

Figure 3. Peabody Housing, Nial Mc Laughlin, London, 2002. $160 \times 119 \mathrm{~mm}(300 \times 300 \mathrm{DPI})$ 
Figure 4. Museum for the Am Römerholz collection from Oscar Reinhart, Gigon \& Guyer, 1998. $33 \times 25 \mathrm{~mm}(300 \times 300$ DPI $)$ 


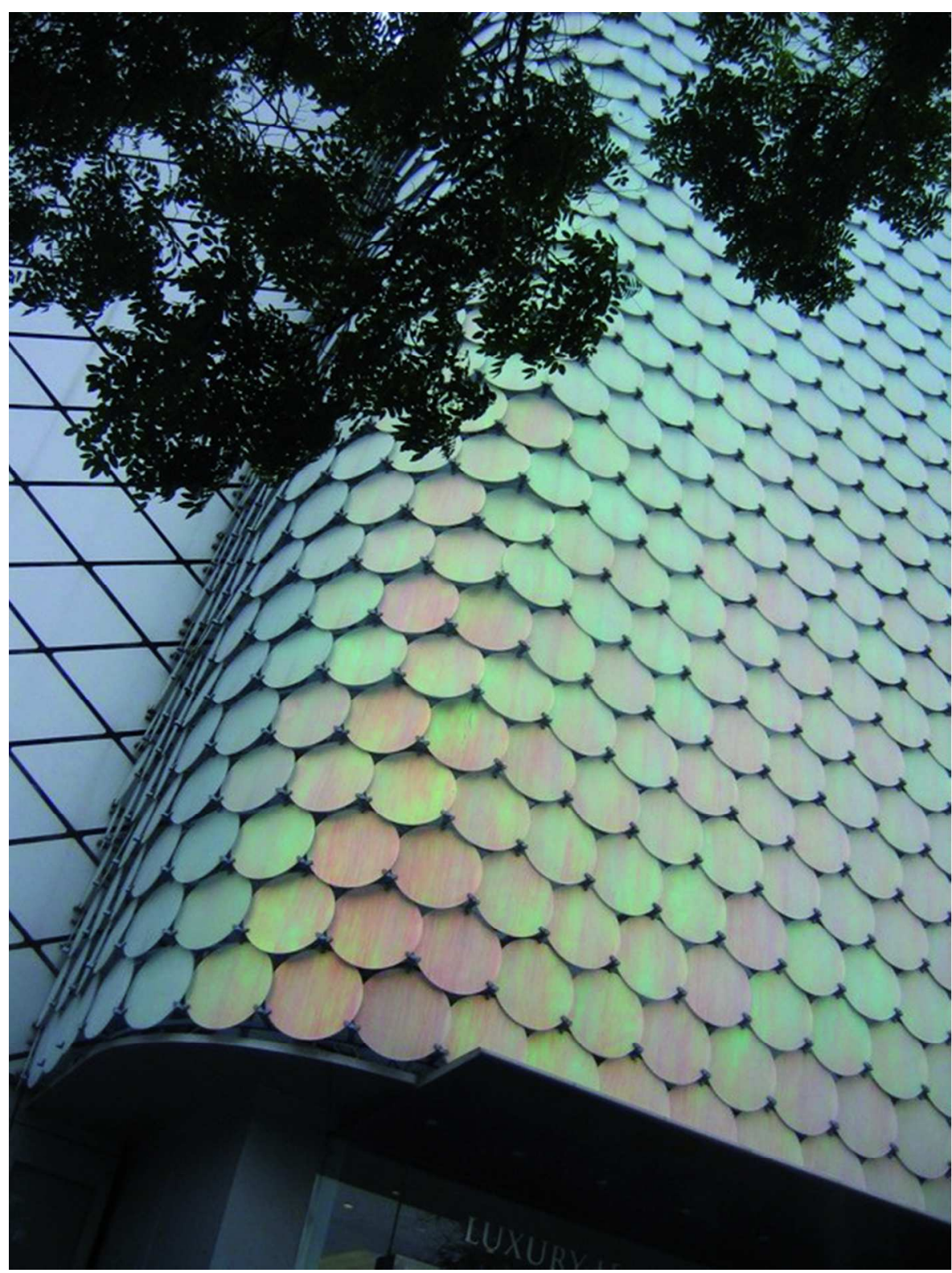

Figure 5. Department store gallery, Ben van Berkel, UNStudio, Seoul, 2004. $50 \times 67 \mathrm{~mm}(300 \times 300$ DPI $)$ 


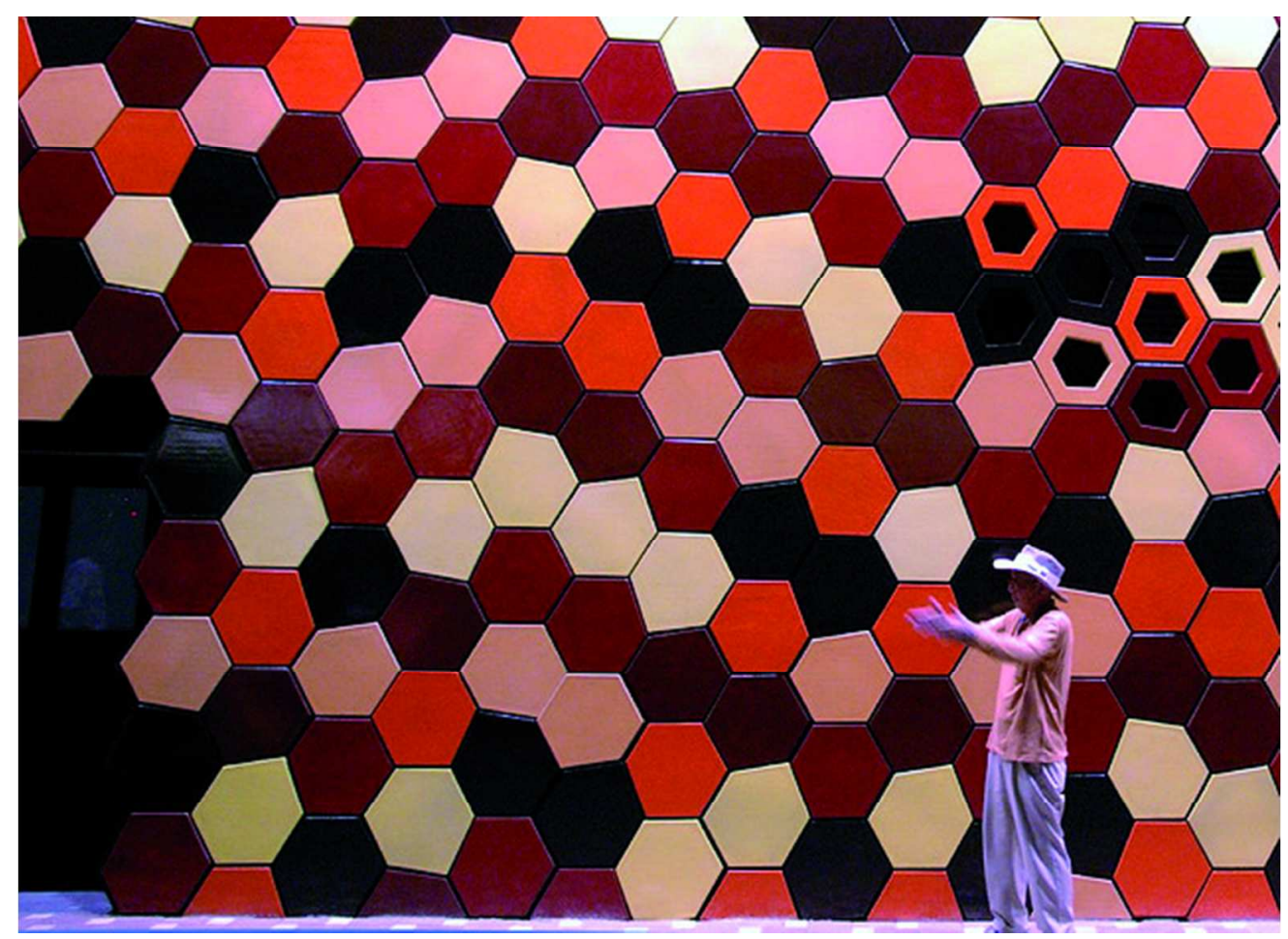

Figure 6. Spanish Pavilion in Expo Aichi, Alejandro Zaera Polo, Japan, 2005. $54 \times 39 \mathrm{~mm}(300 \times 300$ DPI $)$ 


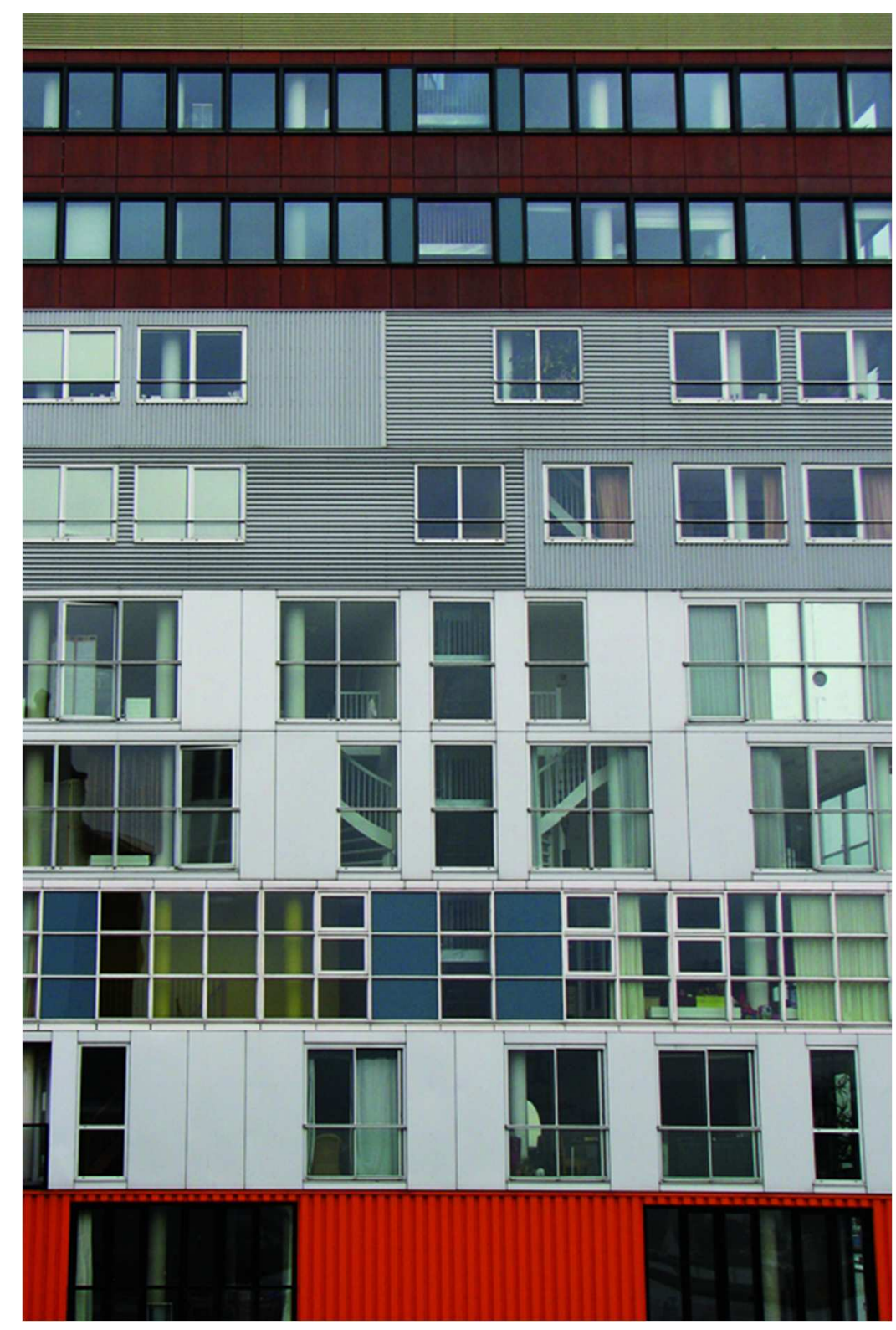

Figure 7. Silodam Building, MVRDV architects, Borneo, Amsterdam, 2002. $46 \times 70 \mathrm{~mm}(300 \times 300 \mathrm{DPI})$ 


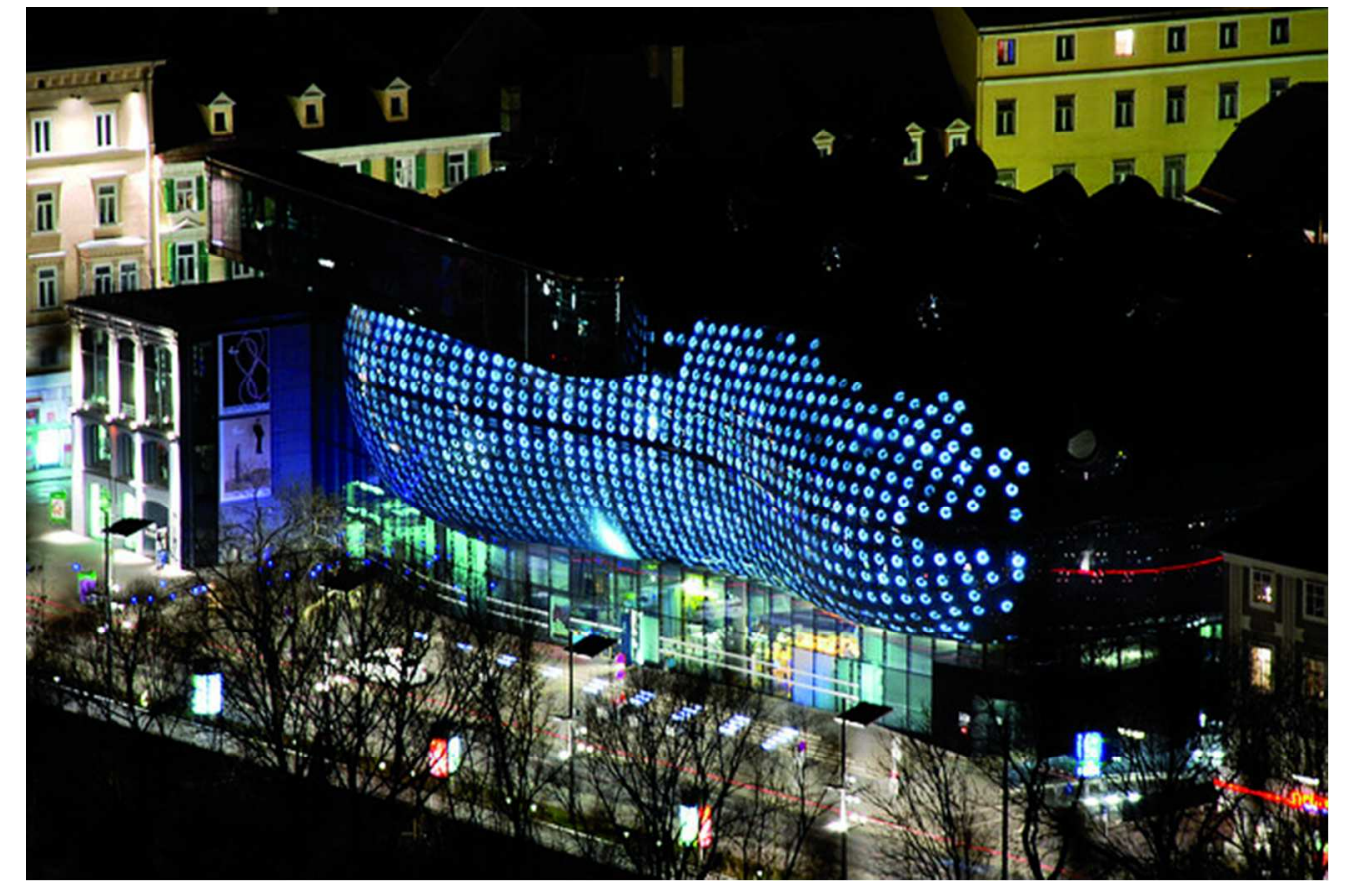

Figure 8. Kunsthaus Graz; Peter Cook, Spacelab UK and Colin Fournier; Graz, Austria, 2003. $54 \times 36 \mathrm{~mm}(300 \times 300 \mathrm{DPI})$ 


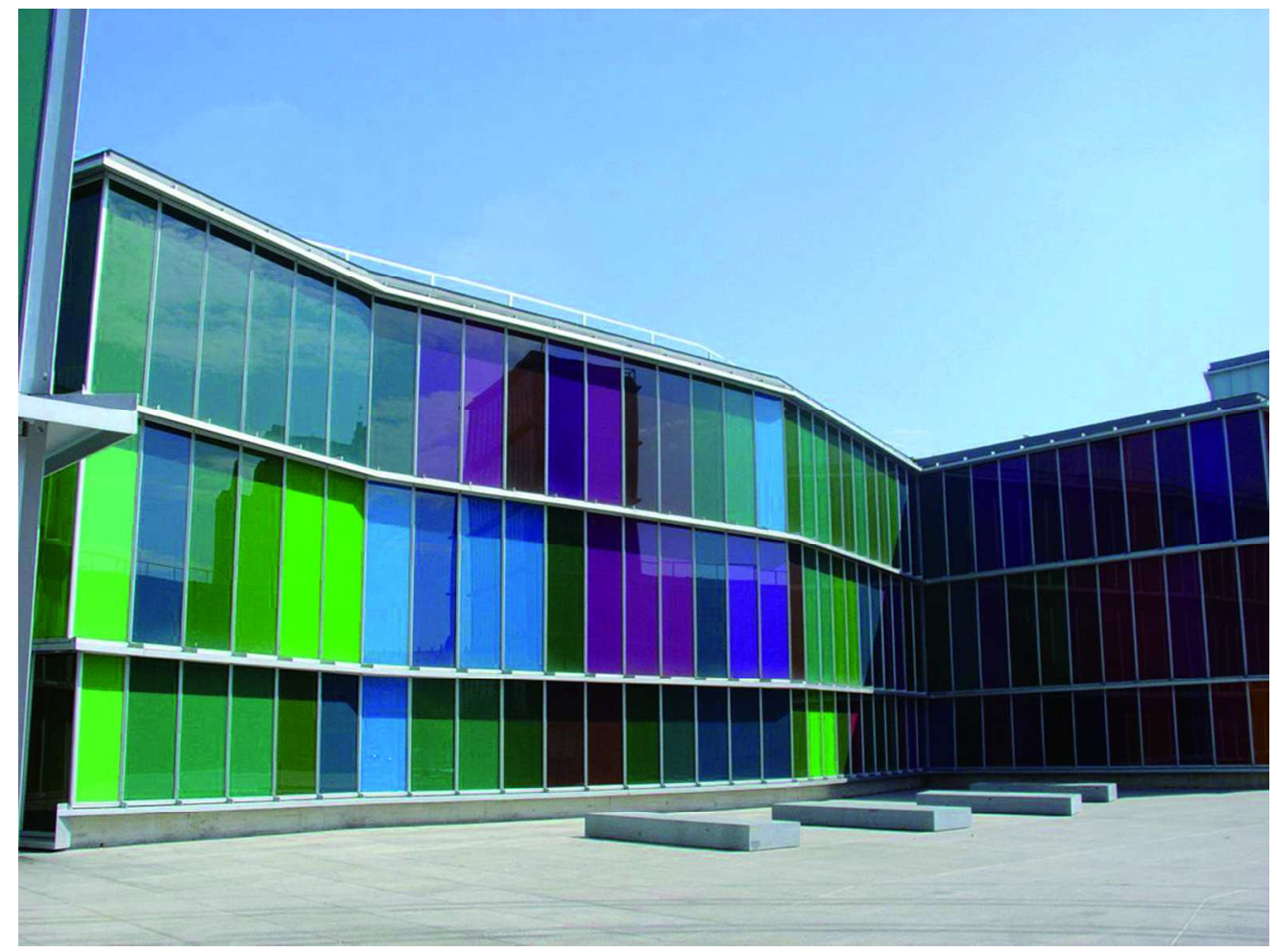

Figure 9. Contemporary art Museum in León, Emilio Tuñón y Luis Moreno Mansilla, León, Spain, 2001-2004 $86 \times 65 \mathrm{~mm}(300 \times 300 \mathrm{DPI})$ 


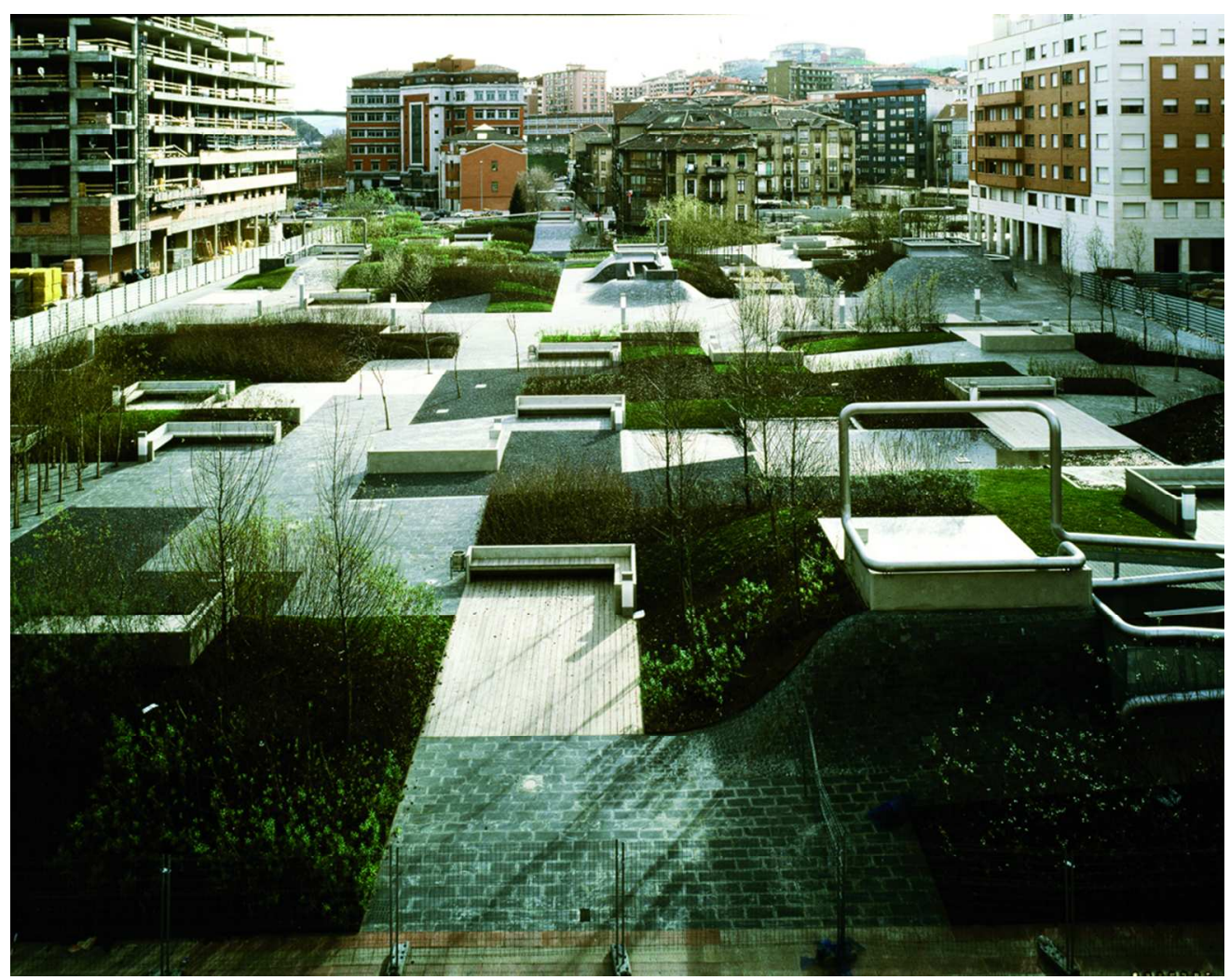

Figure 10. El Desierto Square, Eduardo Arroyo: Nomad, Barakaldo, Vizcaya, Spain, 1999. $93 \times 73 \mathrm{~mm}(300 \times 300$ DPI $)$ 